\title{
unindra
}

Universitas Indraprasta PGRI

Address: Jl. Nangka No. 58 C (TB. Simatupang), Kel. Tanjung Barat, Kec. Jagakarsa, Jakarta Selatan 12530, Indonesia. +62 (021)

7818718 - 78835283; url: www.unindra.ac.id; cultural.syndrome@unindra.ac.id

\section{Sustainable Resource Based Materials in Food Packaging Design}

Nur Hidayah Azhar',

Nor Zalifah Zainal Abidin²

12 Department of Applied Arts and Design,

Kulliyyah of Architecture and Environment

Design, International Islamic University

Malaysia

Correspondence regarding this article should be addressed to:

Nur Hidayah Azhar, dayazhar@gmail.com

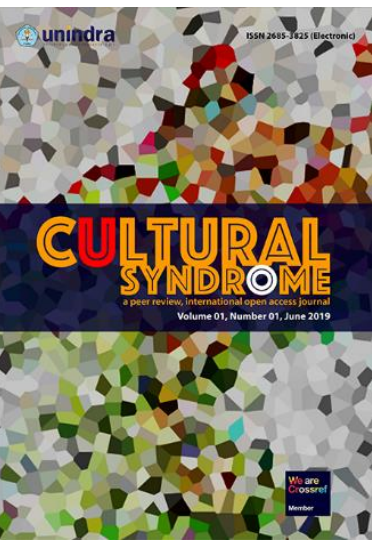

\section{Cultural Syndrome}

Article History

Received : $18-11-2020$

Revised : 25-12-2020

Accepted : 26-12-2020

e-ISSN: 2685-3825

Editor: iD Agung Zainal M. Raden

Publication details, including author guidlines https://journal.unindra.ac.id/index.php/cusy/ about/submissions\#authorGuidelines

\section{How to cite this article (MLA 8th)}

Azhar, Nur Hidayah and Nor Zalifah Zainal Abidin. "Sustainable Resource Based Materials in Food Packaging Design." Cultural Syndrome, vol. 2, no. 2, 2020, pp. 138-149, doi: https://doi.org/10.30998/cs.v2i2.523.

The readers can link to article via https://doi.org/10.30998/cs.v2i2.523

\section{SCROLL DOWN TO READ THIS ARTICLE}

Universitas Indraprasta PGRI (as Publisher) makes every effort to ensure the accuracy of all the information (the "Content") contained in the publications. However, we make no representations or warranties whatsoever as to the accuracy, completeness, or suitability for any purpose of the Content. Any opinions and views expressed in this publication are the opinions and views of the authors, and are not the views of or endorsed by Universitas Indraprasta PGRI. The accuracy of the Content should not be relied upon and should be independently verified with primary sources of information.

\section{(c) (i) (5)}

This work is licensed under a Creative Commons Attribution-NonCommercial 4.0 International License.

Copyright by Nur Hidayah Azhar, Nor Zalifah Zainal Abidin (2020)

The authors whose names are listed in this manuscript declared that they have NO affiliations with or involvement in any organization or entity with any financial interest (such as honoraria; educational grants; participation in speakers' bureaus; membership, employment, consul tancies, stock ownership, or other equity interest; and expert testimony or patent-licensing arrangements), or non-financial interest (such as personal or professional relationships, affiliations, knowledge or beliefs) in the subject matter or materials discussed in this manuscript. This statement is signed by all the authors to indicate agreement that the all information in this article is true and correct 


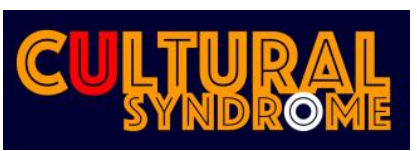

Vol.2, No.2, 2020, pp. 138-149

e-ISSN: 2685-3825

https://doi.org/10.30998/cs.v2i2.523

\title{
Sustainable Resource Based Materials in Food Packaging Design
}

\author{
Nur Hidayah Azhar ${ }^{1}$, Nor Zalifah Zainal Abidin² \\ ${ }^{12}$ Department of Applied Arts and Design, Kulliyyah of Architecture and \\ Environment Design, International Islamic University Malaysia
}

\begin{abstract}
This paper provides and understanding on the utilization of sustainable resources in food packaging. It reviews the negative impacts of plastic and current sustainable materials that are used to substitute plastic in food packaging. In order to replace plastics, many researches have been done to surmount the issue and biodegradable materials such as cellulose, plant fibres, starch based, and any bio-based material have undergone research and experiments to achieve the plastic free food packaging. Moreover, there has been strength and weaknesses in every bio-based material that need to be considered such as its polymer structure and its ability to withstand the outside properties. Different composition and structure of the polymer from this bio-based material determine the shelf life of a food when they are used as the packaging and how it can affect the food. Lesser additives of chemicals used to support the polymer is better. However, much research is still needed in discovering which bio-based material is the most suitable to use as the permanent eco-friendly food packaging design.
\end{abstract}

Keywords: biodegradable, food packaging, packaging design, sustainable, sustainability,

Correspondence author: Nur Hidayah Azhar, dayazhar@gmail.com, Kuala Lumpur, Malaysia

This work is licensed under a CC-BY-NC

\section{Introduction}

Nowadays, a lot of plastic packaging can be seen for food packaging either in supermarket or at a small shop because they play a big role from covering the products until transporting the product. Plastics leaves us with pollution as they took 1000 years to be decomposed and while waiting for that, our landfill will be filled up by other garbage. In the food industry, the usage of plastics has been widely used for every type of goods such as dairy products, frozen foods and household goods. Ma et al. found that the range of plastic being used is on a big scale because of its specialty and flexibility. 
They are keen to attract especially distributors to save cost in producing food packaging. In the study they listed few barriers to get rid of plastic packaging. Big companies that have full control toward packaging manufacturing tend to have problems because it will affect the cost and the whole production process (Ma et al.).

These are the main reason why our ocean is filled with plastics. As stated by The New Plastics Economy (Ma et al.), 32\% of the 78 million tons of world plastic packaging generated annually make their way into our oceans and this is equal to dumping a plastic truck into the ocean every minute. Furthermore, Worm et al. mentioned that evidence also suggests that the high toxicity of plastic contaminants may be passed from the aquatic to the human food chain (Ma et al.). There is enough proof that this financial crisis has to be resolved as a matter of urgency. As indicated by Thompson, owing to the variety and flexibility of plastics, their usage in packaging has risen twenty-fold since the 1900s (Ma et al.). Plastic Europe also suggested that packaging is by far the main product field in the plastics industry and constitutes 39.6 per cent of the global market for plastics (Ma et al.). Hence, plastics packaging needs to be replaced with sustainable material to avoid these conventional plastics to continuously harm our environment in the long-term effect.

\section{Plastics in Packaging}

In this era, many companies are aware regarding the sustainable issue and they have used an alternative to replace the packaging with something renewable such as packaging made up of cardboard, aluminium and bio-based material. As stated in Russel, other types of material that can be recycled also have their own characteristics and have a high chance to become a sustainable packaging. Free from air pollution, greenhouse gas emission and protects human health are the benefits of using the renewable resources as the packaging. In reality, these explain how true and valuable they can be but the solutions they came up with are not being used and do not fulfil the sustainable criteria (Russell). He continued by informing that to succeed in packaging particularly for food packaging, the packaging needs to be in a good condition without posing a health risk to the consumers' health. From the existing data, the factors that need to be stressed out involve material selected in the packaging design process, material that has been used as packaging needs to be an example as well as replacement to plastic in packaging design. The result from the survey proves that these are the important aspects that need to be taken into consideration.

The usage of plastics in packaging are global Schmidt Rivera et al. stated that plastic packaging accounts for $26 \%$ of the overall chemicals produced and about $72 \%$ of these products are actually discarded, with $40 \%$ in landfills and $32 \%$ in rivers and industrial environments. In comparison, the global output of plastics accounts for $6 \%$ of the world's oil consumption. Rivera continued by stating that while the rate of plastic recycling has risen, only 14 per cent is recycled and only 5 per cent of the material expense is maintained after further treatment.

In food packaging design, packaging helps food to maintain it shelf life and save it from its loss. However, plastics used as their packaging and contributes to the 
environmental issue creates a problem with the production and resources. Rivera has specified that "packaging helps to reduce food waste by protecting food, reducing its losses and prolonging its shelf life. However, packaging has also become an environmental burden, particularly single-use plastics, due to its reliance on fossil fuel resources and lack of appropriate waste management practices". With that information, she concludes that packaging gives benefit in order to elongate the shelf life of a food but there are problems with the plastics used as it packaging (Schmidt Rivera et al.).

Besides, Magnier et al. mentioned in their articles that many consumer goods are packed for sale and thus their environmental impact relies not just on the products itself, but also the packaging. Also, the underlying characteristics and the originate qualities of the commodity (e.g., packaging) should be modified to save the environmental impact of the company. They also described that maintaining the environmental sustainability is important as an attempt to reduce the environmental pollutions by these qualities that are not belong to them and therefore the alternative packaging quality substance must lack of toxic additives and using the organic ingredients. They stated that "packaging sustainability is defined as the endeavour to reduce the product's footprint through altering the product's packaging, for example, by using more environmentally friendly materials". With the statement, they agreed that material for food packaging is the key to remain sustainability. Therefore, conventional plastics packaging can be swap with biodegradable materials that can be used to derives plastics (Magnier et al.).

\section{Alternative Materials for Plastic Packaging}

In order to obtain sustainability, the usage of conventional plastics need to be replaced with biodegradable plastics. American Chemistry Council stated that plastic has been used since 1862 revealed by Alexander Parkes and was a biodegradable plastic (American Chemistry Council). Polymers that are known as one of the materials to make plastics have many types and can also derive from plants. As stated by Nesic et al.:

"Starch, in addition to cellulose, is the most prevalent carbohydrate in nature and as such is one of the basic nutrients and sources of energy. Starch is found in all green plants. By photosynthesis, from carbon dioxide and water, is created glucose that produces starch by enzymatically catalysed polymerization. The main plant sources of production are potato, corn, and rice. In all plants, the starch is produced in the form of granules, of different sizes and of somewhat different composition, depending on the plant" (Nesic et al.)

With that information, it explains that starch derives from natural resources which are plants and have different characteristics depending on what types of plants it comes from. Plus, starch has been known as one of the materials that have polymer and can be used and turned into plastic. As Jiang mentioned in their article, "starch is one of the most promising natural polymers because of its inherent biodegradability, overwhelming abundance and annual renewability". With this information, it answers the question why starch is being used as packaging. Starches caught the inventor's attention because their polymers are cost efficient and able to withstand the conventional 
plastic packaging process (【iang et al.). Khalil (Ma et al.) declared in his article that it is necessary to invent new materials to get rid of conventional plastics. For production, the usage of plastics will be minimized by replacing the current plastic packaging system with recycled boards and containers (Ma et al.). Thus, sustainable issue can be solved by creating biodegradable material or recycle and reuse their goods.

Firstly, as mentioned above, starch is also known for its biodegradability to offer as a new material for plastic packaging. Due to extensive use of petrochemical derived polymers, the production and application of biodegradable starch-based material has attracted attention since the problems of oil shortages and increase the growing interest in easement of environmental burden (Jiang et al.). Other than that, he stated that the intricate microstructures of other starches and their transition phase during one of the processes known as thermal processing enhanced the basic knowledge of polymer science. It is well established that organic polymer methods have developed microstructures that can be engineered and regulated the weight distribution and molecular weight. They said that starch stores carbon through its polysaccharide and it contains intracellularly spherical granules. Moreover, corn, rice, wheat, cassava (tapioca) and potato are examples of accessible starch that have been imposed as the material for sustainable food packaging design. There are few ways to achieve the end product by experimenting with its physical and chemical properties and undergo the chosen process such as "water diffusion, granule expansion, gelatinization, decomposition, melting and

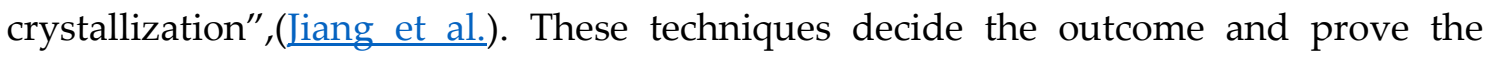
strength and expose the weaknesses of the starch and improvement can be made.

Secondly, improvement has been made to create a plastics' environment efficient and biobased material like nanocomposites and nanoparticles (Vilarinho et al.). He added that biopolymers have their own weaknesses in their mechanical and barrier properties hence they used nano-sized components to strengthen the biopolymers and form nanocomposites. Cellulose as being stated by Vilarinho as the most recommended and famous renewable resources have a better specs in mechanical properties, strength, quality, and biodegradability. Klemm's article mentioned that cellulose has engaged the attention recently as one of the popular renewable and ecological raw materials for gaining obtaining technological products which are environmentally friendly and biocompatible. Photosynthetic species that formed biomass are highly demanded biopolymers on earth which are made up of plants, algae and other bacteria which contain cellulose (Klemm et al.; Vilarinho et al.). Thus, options to use bionanomaterials in food packaging replacing the plastics particularly the oil-based one are promising.

Other than that, green nanocomposite also categorized into the nanocellulose materials. Hai mentioned in in his study that "good biodegradability and biocompatibility of chitin in conjunction with good mechanical properties of cellulose are beneficial for developing green nanocomposite applicable for food packaging". With that information, it is well said that nanocomposite needs more study and suitable for food packaging. Nanocomposite production can be created simply by blending different mechanical and physical properties of chitin nanofiber (CTNF) and bamboo cellulose nanofiber (BACNF). The most common substance on earth which is cellulose has long 
been used for many aims and purposes and already went through different level such as paper, constructions, additives, pharmaceutics, coatings and composite (Hai et al.). Hai defined that cellulose nanofiber raised interest because of its specialty which is lightweight, high tensile strength, high Young's modulus, environmentally friendly, recyclable and profusion ( may be extracted from a range of resources such as wood, non-wood plants, marine algae and cellulose bacteria. Cellulose nanofiber is suitable for advanced applications such as material reinforcement, intelligent materials and new value goods.

Next, the other prominent material that can be used as material to replace the conventional packaging is Chitosan-based. Priyardarshi and Rhim mentioned that "Chitosan, a deacetylated derivative of chitin, can be obtained by deacetylation of chitin. It is a functionally versatile biopolymer due to the presence of amino groups responsible for the various properties of the polymer. Although it has been used for various industrial applications, the recent one is its use as a biodegradable antimicrobial food packaging material". With this information, it proves that Chitosan-based has already been introduced and implemented in the industry. Every year, a vast number of crustacean shells has been produced and they can be used to generate value-added chitin that can be made over into chitosan by using a fairly easy deacetylation method (Priyadarshi and Rhim). They added, compared to other biopolymer, chitosan is much lower cost compared to the other biopolymer because it comes from bio-waste plants that use the process called energyefficient. Meanwhile, Hai declared in his article that chitin is the second most abundant cellulose biopolymer on earth, collected from crab, shrimp and lobster shell. He added that chitin's uses have included food additives, food processing, cosmetics, composites, textiles, plastics, biosensors and drug delivery, due to its high biocompatibility, biodegradability, nontoxicity and multifunctionality characteristics (Hai et al.). Moreover, chitin was used in the production of commercial products of chitin or cellulose composites developed through the spinning of cellulose viscose. Therefore, much research needs to do that relate with chitosan-based as material for food packaging design.

\section{Methods}

The methodology applied in this paper referred to the existing data collected that has been done by previous researchers. Comparison is being made from existing research papers and products for research papers from 2012-2020. This section talked about the methods used to gather and examine data for this study. The data gathered that is being collected display the frame of this research paper.

\section{Data Collection}

There are several ways that have been conducted to collect data such as survey, evaluation, analysis, or examination of a paper. Previous work that was relevant to the topic is being illustrated in this paper. Primarily the data gathered is from the internet 
and done through reviewing past research papers. Reviewing data in past research papers selected from 2012-2020 and is the most suitable method for this research paper. In Bowen's articles, data processing is an easy and reliable method to gather evidence, since reporting is accessible and realistic. He added that records are ubiquitous and come in a number of ways, rendering records a highly open and accurate data base. Therefore, having a document review is not an issue as the main method for this paper (Bowen; Triad).

\section{Result and Discussion}

\section{Theoretical implications}

This study was designed to answer how importance to identify and applied the materials that are biodegradable to replace the conventional plastics packaging. The importance of having a packaging is very high because they are part of the supply chain and in order to remain safe, packaging itself need to be in a good shape because packaging has a small effect on the atmosphere relative to its product (Russell). They also mentioned that when designing more sustainable packaging, it is important to carry out and assess rigorous assessments that consider the entire service life cycle and take a systemic, anthropogenic view of sustainability, including its overall social and economic consequences beyond conventional environmental metrics. He added that the climate, culture and the economy sustainability dimensions are interdependent and conflicting. This Triple Bottom Line has to be addressed by community, both through and sharing quality of life gains more equitably but at the same time reducing the adverse impact of the eco-system on both the short and long term over the whole life cycle of products and services.

\section{Sustainable Material for Food Packaging Design}

Sustainable materials in packaging and product is a way in maintaining the environment as well as attracted consumer in rising the economy. A study by Abidin et al. specified that "the material used for the packaging has also become more advanced and complicated. Green technologies have become popular as a friendlier method in producing better packaging". With this information, it is proved that in the market, the involvement of food packaging design that use green technologies has been important in order to conserve the environment (Abidin et al. $)$. Russell had mentioned in his article that a deeper emphasis on supply chains and their goods and services makes it easier to believe that a good or service's long-term market viability is likely to improve when perceived from a systemic, life-cycle viewpoint which are; biosphere is sustained, resources still available, society is improved, does not risk human and boost the dynamics of the delivery of supply chain facilities to end-users. Economy boost and market base are important as well to prove that sustainable products are a success that need to be maintained and also add that all of these issues need to be focused on and view it in other perspective, and taking full life cycles into account regarding 
components and services that is related in the value chain to deliver particular product or service to the consumer (Russell). As for the examples, he said that the agricultural products are basically the main bio-based raw materials that could be food (e.g., maize) because their chemical properties are easier to be converted, simplified and cost efficient.

Tabel. Displays the bio-based materials that can replace the conventional plastics packaging

\begin{tabular}{|c|c|c|c|}
\hline Materials & Applications & Food Examples & Main Suppliers and Products \\
\hline *PLA & $\begin{array}{l}\text { Transparent thermoformed } \\
\text { trays and films } \\
\text { Bags } \\
\text { Cups (PLA-based foam) } \\
\text { Cups and bottles } \\
\text { Trays }\end{array}$ & $\begin{array}{l}\text { Fruits and vegetables (e.g., } \\
\text { strawberries, pepers, } \\
\text { lettuce) } \\
\text { Teabags and bread } \\
\text { Hot drink (e.g., coffee from } \\
\text { vending machines) } \\
\text { Dairy Products (e.g., yogurt } \\
\text { and milk) } \\
\text { Ice cream }\end{array}$ & $\begin{array}{l}\text { Natureworks (Ingeo); } \\
\text { Corbion; } \\
\text { Futerro; } \\
\text { BASF (Ecovio; Ecoflex); Fkur } \\
\text { (Bioflex); } \\
\text { Synprodo (Biofoam) }\end{array}$ \\
\hline PHA & Films and tray & Frozen foods and fresh meat & $\begin{array}{l}\text { Metabolix (Mirel); } \\
\text { Tianan (Enmat); } \\
\text { Biomer; } \\
\text { TGBM (Sogreen) }\end{array}$ \\
\hline Starch & $\begin{array}{l}\text { Translucent Film } \\
\text { Covering films with barrier } \\
\text { fuction } \\
\text { Containers }\end{array}$ & $\begin{array}{l}\text { Fruits and vegetables (e.g., } \\
\text { potatoes and carrots) } \\
\text { Meat, fish } \\
\text { (starch derivate/Plantic); } \\
\text { Cheese (Plantic and Mater- } \\
\text { b) } \\
\text { Confectionary (Plantic) }\end{array}$ & $\begin{array}{l}\text { Biotec (Bioplast); } \\
\text { Novamont (Mater-bi); } \\
\text { Plantic (Plantic and eco } \\
\text { Plastic) }\end{array}$ \\
\hline Cellulose & 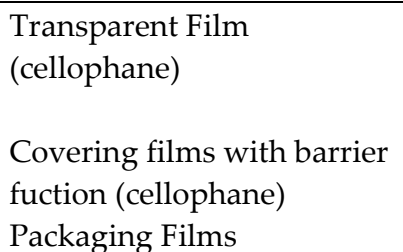 & $\begin{array}{l}\text { Fruits and vegetables (e.g., } \\
\text { potatoes and bell peppers) } \\
\text { Meat, fish, chesse } \\
\text { Butter, bread, coffee }\end{array}$ & $\begin{array}{l}\text { Fkur; } \\
\text { Innovia (cellophane) and } \\
\text { (NatureFlex) }\end{array}$ \\
\hline
\end{tabular}

*PLA, Polylactic Acid; PHA, Polyhydroxyalkanoate

Source: (Ramos et al.)

Based on Table 1, these are the biodegradable materials that has being tested and used for food packaging. It has been applied in various ways starting from a layer of a film until it becomes a full packaging design for food industry. The range of food that used biodegradable material as its packaging are milk and dairy products, fruit and vegetables, frozen food and fish, meat and butchery, and bakery.

The main suppliers and products are companies that involves in those categories that used these food range. Moreover, this table shows that these biodegradable material scales of application are in massive range that has already being applied in the industry consider the safety and procedure. Hence, cost efficiency makes a big distributor and manufacturer used this application to save cost as well as saving the environment. 
Table 2 The Characters that need to be considered for sustainable food packaging material

\begin{tabular}{|c|c|c|}
\hline Demand area & Time and place & Attributes \\
\hline Fuction & Conception & $\begin{array}{l}\text { Containment, communication, } \\
\text { convenience }\end{array}$ \\
\hline \multirow[t]{4}{*}{ Environment } & Food Production & $\begin{array}{l}\text { Emmisions, effluents, waste, } \\
\text { energy consumption }\end{array}$ \\
\hline & Packaging & $\begin{array}{l}\text { Resource, package size, weight, } \\
\text { reuse, recycle, disposal }\end{array}$ \\
\hline & Distribution and Marketing & $\begin{array}{l}\text { Temperature, shelf life, } \\
\text { transportation }\end{array}$ \\
\hline & Consumer & $\begin{array}{l}\text { Storage temperature, } \\
\text { preparation, food waste }\end{array}$ \\
\hline \multirow[t]{4}{*}{ Society } & Food Production & Preference for local food \\
\hline & Packaging & Hygienic safety \\
\hline & Distribution and Marketing & $\begin{array}{l}\text { Fair-trade, government policy, } \\
\text { shelf life control }\end{array}$ \\
\hline & Consumer & $\begin{array}{l}\text { Attitude on accepting recycled } \\
\text { products, willingness to sacrifice } \\
\text { convenience for environmentally } \\
\text { friendly packaging }\end{array}$ \\
\hline Economics & All phases & $\begin{array}{l}\text { Cost-effectiveness, } \\
\text { resources }\end{array}$ \\
\hline
\end{tabular}

Source: (

Table 2 shows that the characteristics that need to be considered in designing a sustainable food packaging design. Designing a sustainable food packaging is not just by making a modification towards the design. Systematic optimization is required as well as its construction and ecosystem's integrated viewpoint.

The function and effect of packaging on the eco-system and its ecosystem should be better balanced and adequate packaging efficiency and waste management should be pursued in the sense of the whole method, with low environmental effects (Han et al.). Maxwell and Vorst stated in his article, Consequently, sustainability can also be treated as a comprehensive term, taking due account of the climate, culture, economy and work (Han et al.; Maxwell and van der Vorst).

In the industry, attraction of starch-based material is increasing and they have applied it the market to ease the environment as well as reducing the oil usage to process conventional plastics. Figure below shows the examples of starch-based materials that has been used in replacing the conventional plastics. 


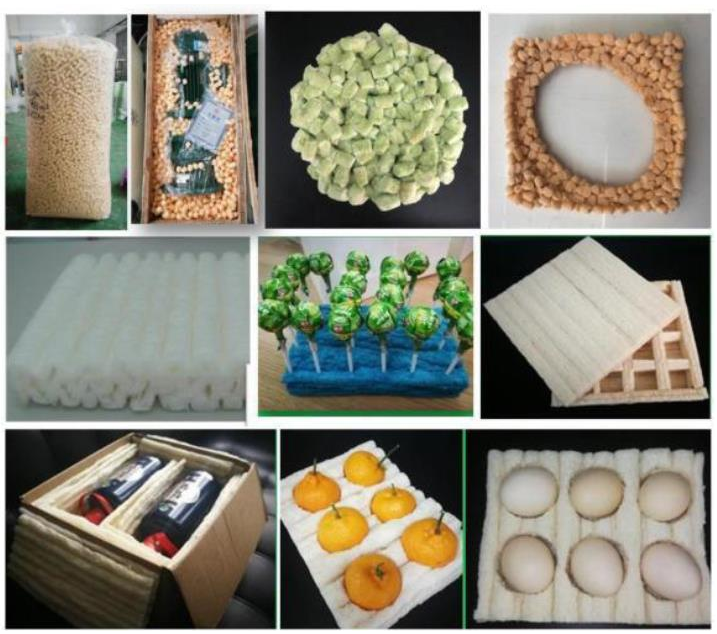

Figure 1 The examples of starch-based materials that has been replacing the conventional plastic packaging.

Source: (监g et al.)

Figure 1 shows that more companies in their respective countries has taken this initiative which is using the commercialized starch items. By adopting restrictions and falls by prohibiting waste plastics, more starch-based packaging is being produce. Past experiments have shown that starch is a heterogeneous substance with two compounds kinds of microstructures: linear and branched. Natural physical starch mostly has bulky semi-crystalline. Jiang mentioned that the tools decide the crystallinity and it is about 20-45 per cent. The recuperation of the crystalline lead by the short-branched chains in amylopectin of the crystalline and exist in the shape of double helices with a duration of $\sim 5 \mathrm{~nm}$. Throughout the crystalline regions the amylopectin fragments are mostly similar to the broad helix axis (Jiang et al.).

Han had avowed that the overall used of packaging materials during the packaging life cycle can be minimized with the structure design and dimensional changes. Thus, considering about the biodegradable development, compostable, edible and other active packaging material are important for the combination of design innovation with the packaging material ( that an efficient guideline for the eco-design food and beverage packaging, involving eco-efficiency tactics, recycling design, composting design, the avoidance of poison substance and environmental communication (Han et al.; Lewis). As found by Doanne, they defined that bio-disintegrable plastics are formed by combining naturally degradable compounds like corn starch with synthetic polymers and other degradation catalyst to rise their degradability. they added that although biodegradable plastics are not expensive, they cannot be used for food packing ages due to their lower durability and strength, which restricts their use in shopping bags and garbage bags. Even so, these biodegradable plastics still give contribution to sustain the environment and categorized as packaging for transport food that is also necessary for consumer (Doane; Han et al.).

Hence, more research and study that focus on sustainable material and polymer combination need to be done through experiments to invent new materials that is easy 
to be decomposed as well as can be an initiative to replace conventional plastics. It may take longer time to successfully found the solution but it could save the future. Cost and other implications need to bear in mind as well because these involve a big change to the environment. In other point of view, other perspectives such as the source for these biodegradable materials need to be considered as well to avoid human from taking only advantage and leaves harm to the environment.

\section{Conclusion}

To conclude, we note that few boundaries in this study that offer chances for potential study in future. First, further work could be done to explore other materials of biodegradable materials that derives from plant and other renewable resources. There are already bioplastics packaging that is constructing from bio-based materials. Visual appearance is also importance to depict the strength and durability of the bioplastics. Improvement can be made after testing out the plastics. These bio-based materials have a high chance of being renewable and biodegradable. Other than that, it also uses a low cost because they are renewable and many of them are being made.

Next, the awareness is also important by the massive companies to replant or having a place where they have their own source. The increasing of natural renewable source and use their cellulose or starch to create the bio-based material is important to save the environment. The importance of using the materials that are eco-friendly is because to preserve our environment from being exhausted with the pollution and destruction that lead to the end of the world.

\section{References}

Abidin, Sazrinee Zainal et al. "A Semantic Approach in Perception for Packaging in the Sme's Food Industries in Malaysia: A Case Study of Malaysia Food Product Branding in United Kingdom." Procedia - Social and Behavioral Sciences, vol. 115, 2014, pp. 115-130, doi:https://doi.org/10.1016/j.sbspro.2014.02.420.

American Chemistry Council. "Plastic Packaging History: Innovations through the Decades." 2018. https://www.plasticsmakeitpossible.com/about-plastics/historyof-plastics/plastic-innovations-in-packaging-through-the-decades/ .

Bowen, Glenn A. "Document Analysis as a Qualitative Research Method." Qualitative Research Journal, vol. 9, no. 2, 2009, pp. 27-40, doi:https://doi.org/10.3316/QRJ0902027.

Doane, William M. "Usda Research on Starch-Based Biodegradable Plastics." Starch Stärke, vol. 44, no. 8, 1992, pp. 293-295, doi:https://doi.org/10.1002/star.19920440805. 
Hai, LeVan et al. "Green Nanocomposite Made with Chitin and Bamboo Nanofibers and Its Mechanical, Thermal and Biodegradable Properties for Food Packaging." International Journal of Biological Macromolecules, vol. 144, 2020, pp. 491-499, doi:https://doi.org/10.1016/j.ijbiomac.2019.12.124.

Han, J. H. et al. "Eco-Design of Food and Beverage Packaging." edited by Kit L. Yam and Dong Sun B. T. Emerging Food Packaging Technologies Lee, Woodhead Publishing, 2012, 361-379. http://www.sciencedirect.com/science/article/pii/B978184569809650018X.

Jiang, Tianyu et al. "Starch-Based Biodegradable Materials: Challenges and Opportunities." Advanced Industrial and Engineering Polymer Research, vol. 3, no. 1, 2020, pp. 8-18, doi:https://doi.org/10.1016/j.aiepr.2019.11.003.

Klemm, Dieter et al. "Cellulose: Fascinating Biopolymer and Sustainable Raw Material." Angewandte Chemie International Edition, vol. 44, no. 22, 2005, pp. 3358-3393, doi:https://doi.org/10.1002/anie.200460587.

Lewis, H. "10 - Eco-Design of Food Packaging Materials." Environmentally Compatible Food Packaging, edited by Emo Chiellini, Woodhead Publishing, 2008, pp. 238262. http://www.sciencedirect.com/science/article/pii/B9781845691943500106.

Ma, Xuezi et al. "Factors for Eliminating Plastic in Packaging: The European Fmcg Experts' View." Journal of Cleaner Production, vol. 256, 2020, p. 120492, doi:https://doi.org/10.1016/j.jclepro.2020.120492.

Magnier, Lise et al. "Judging a Product by Its Cover: Packaging Sustainability and Perceptions of Quality in Food Products." Food Quality and Preference, vol. 53, 2016, pp. 132-142, doi:https://doi.org/10.1016/j.foodqual.2016.06.006.

Maxwell, D. and R. van der Vorst. "Developing Sustainable Products and Services." Journal of Cleaner Production, vol. 11, no. 8, 2003, pp. 883-895, doi:https://doi.org/10.1016/S0959-6526(02)00164-6.

Nesic, Aleksandra et al. "Bio-Based Packaging Materials." edited by Charis M. B. T. Biobased Products Galanakis and Industries, Elsevier, 2020, pp. 279-309. http://www.sciencedirect.com/science/article/pii/B9780128184936000087.

Priyadarshi, Ruchir and Jong-Whan Rhim. "Chitosan-Based Biodegradable Functional Films for Food Packaging Applications." Innovative Food Science \& Emerging Technologies, vol. 62, 2020, p. 102346, doi:https://doi.org/10.1016/j.ifset.2020.102346.

Ramos, Ó.L. et al. Advances in Processing Technologies for Bio-Based Nanosystems in Food. CRC Press, 2019. 
Russell, David A. M. "Sustainable (Food) Packaging - an Overview." Food Additives $\mathcal{E}$ Contaminants: Part A, vol. 31, no. 3, 2014, pp. 396-401, doi:https://doi.org/10.1080/19440049.2013.856521.

Schmidt Rivera, Ximena C. et al. "Aiding the Design of Innovative and Sustainable Food Packaging: Integrating Techno-Environmental and Circular Economy Criteria." Energy Procedia, vol. 161, 2019, pp. 190-197, doi:https://doi.org/10.1016/j.egypro.2019.02.081.

Triad. "An Introduction to Document Analysis." 2016. https://lled500.trubox.ca/2016/244https://lled500.trubox.ca/2016/244.

Vilarinho, Fernanda et al. "Nanocellulose in Green Food Packaging." Critical Reviews in Food Science and Nutrition, vol. 58, no. 9, 2018, pp. 1526-1537, doi:https://doi.org/10.1080/10408398.2016.1270254. 